\title{
Different magnitudes of projected subsurface ocean warming around Greenland and Antarctica
}

\author{
Jianjun Yin ${ }^{1 \star}$, Jonathan T. Overpeck', Stephen M. Griffies ${ }^{2}$, Aixue Hu${ }^{3}$, Joellen L. Russell ${ }^{1}$ \\ and Ronald J. Stouffer ${ }^{2}$
}

The observed acceleration of outlet glaciers and ice flows in Greenland and Antarctica is closely linked to ocean warming, especially in the subsurface layer ${ }^{1-5}$. Accurate projections of ice-sheet dynamics and global sea-level rise therefore require information of future ocean warming in the vicinity of the large ice sheets. Here we use a set of 19 state-of-the-art climate models to quantify this ocean warming in the next two centuries. We find that in response to a mid-range increase in atmospheric greenhouse-gas concentrations, the subsurface oceans surrounding the two polar ice sheets at depths of 200-500 m warm substantially compared with the observed changes thus far $^{6-8}$. Model projections suggest that over the course of the twenty-first century, the maximum ocean warming around Greenland will be almost double the global mean, with a magnitude of $1.7-2.0^{\circ} \mathrm{C}$. By contrast, ocean warming around Antarctica will be only about half as large as global mean warming, with a magnitude of 0.5-0.6 ${ }^{\circ} \mathrm{C}$. A more detailed evaluation indicates that ocean warming is controlled by different mechanisms around Greenland and Antarctica. We conclude that projected subsurface ocean warming could drive significant increases in ice-mass loss, and heighten the risk of future large sea-level rise.

Recent rapid mass loss of the Greenland Ice Sheet (GIS) is attributable to the acceleration of Greenland outlet glaciers ${ }^{1,2}$ that was primarily triggered by subsurface ocean warming ${ }^{3-5}$. Since the 1990 s, the land-terminating glaciers have showed no significant change $^{9}$, in sharp contrast to the rapid retreat of the tidewater glaciers with deep submarine beds $s^{1,3-5}$. Many Greenland fjords where outlet glaciers terminate reach several hundred to one thousand metres depth at the grounding lines ${ }^{3,4}$. Warm and salty North Atlantic subtropical waters could penetrate from the shelf into the deep fjords, remain in the subsurface layer year-round and flush rapidly through local wind-driven circulation ${ }^{4}$, thereby giving a 'warm bath' to the ice sheet. In the Southern Hemisphere, the marine-based West Antarctic Ice Sheet (WAIS) and the floating ice shelves are inherently sensitive and vulnerable to ocean warming ${ }^{10}$. The recent thinning of the ice shelves and the acceleration of ice flows $^{11,12}$ have been too fast to be explained by the atmospheric warming only ${ }^{7}$. Therefore, quantifying future ocean warming around Greenland and Antarctica is critical to understanding icesheet dynamics and predicting global sea-level rise.

Most previous simulations and projections of the melting of polar ice sheets focused on the atmospheric warming and its impact on surface mass balance ${ }^{13-15}$. Here we use 19 state-of-the-art climate models (Supplementary Table S1) to examine future ocean warming around the ice-sheet periphery in response to the increase in greenhouse-gas concentrations (see the Methods section). In the current climate, both the Greenland and Antarctic ice sheets are surrounded by frigid sea waters close to the freezing point. The East and West Greenland Current (EGC and WGC) carry cold and fresh Arctic waters around Greenland in the upper ocean, keeping the warm North Atlantic subtropical waters offshore (Fig. 1a). In the Southern Ocean, the combination of a strong Antarctic Circumpolar Current (ACC) and upwelling of cold deep water prevents poleward intrusion of the warm subtropical water and associated heat transport (Fig. 1b).

The multi-model ensemble mean projection shows that ocean warming over the twenty-first and twenty-second century is spatially very different (Fig. 1 and Supplementary Fig. S1). A large warming occurs in the subsurface ocean $(200-500 \mathrm{~m})$ surrounding Greenland (Figs 2 and 3). For the twenty-first century, the mean warming reaches $2.0 \pm 1.1^{\circ} \mathrm{C}, 1.7 \pm 1.1^{\circ} \mathrm{C}$ and $1.8 \pm 1.1^{\circ} \mathrm{C}$ along the land-ocean boundary of NE, SE and W Greenland, respectively (Fig. 2a). These values are almost double the global ocean warming of about $1.0 \pm 0.3^{\circ} \mathrm{C}$ in the same layer, and are comparable to the global atmospheric warming of $2-3^{\circ} \mathrm{C}$ at the surface ${ }^{16}$. The probability of $>3^{\circ} \mathrm{C}$ and $>6^{\circ} \mathrm{C}$ ocean warming around Greenland cannot be excluded by 2100 and 2200, respectively (Fig. 2b). Thus in the future, the warm intermediate waters approach the GIS from below and can cause strong basal melting of outlet glaciers, significantly changing their dynamics (Fig. 3). Models show large uncertainty around Greenland, as indicated by the wide spread between the projections (Fig. 2 and Supplementary Fig. S2).

By contrast, the Antarctic Ocean undergoes a mean warming about half of the global mean, with a magnitude of only $0.6 \pm 0.4{ }^{\circ} \mathrm{C}$ at E Antarctica and $0.5 \pm 0.4^{\circ} \mathrm{C}$ at $\mathrm{W}$ Antarctica by 2100 and about $1{ }^{\circ} \mathrm{C}$ by 2200 (Fig. 2). Nonetheless, this means all of the Antarctic margin will be bathed in significantly warmer waters in the future (Fig. 1), probably amplifying the impacts on the Antarctic Ice Sheet (AIS) relative to the more geographically restricted and moderate warming seen thus far ${ }^{6,7}$. We next use the GFDL CM2.0 and CM2.1 climate models ${ }^{17}$ (see the Methods section), the projections of which are relatively high and low in the ensemble range (Fig. 2), respectively, to understand the detailed mechanisms and model differences.

For the GIS, the coastal waters at its NE margin are the coldest $\left(\sim 1^{\circ} \mathrm{C}\right)$ at present ${ }^{18}$ (Fig. 1a). The warm Atlantic inflow across the Iceland-Scotland ridge loses much heat to the overlying atmosphere when circulating with the Greenland Sea gyre (Supplementary Fig. S3). The cold recirculating Atlantic water subducts and feeds into the EGC, flowing southward in the intermediate layer (below $200 \mathrm{~m}$ ) along NE Greenland (Supplementary Figs S4 and S5). During the twenty-first century, the ocean surface heat loss in the Nordic Seas reduces by 36 and 29 TW $\left(1 \mathrm{TW}=10^{12} \mathrm{~W}\right)$ in

${ }^{1}$ Department of Geosciences, University of Arizona, 1040 E 4th Street, Tucson, Arizona 85721, USA, ${ }^{2}$ Geophysical Fluid Dynamics Laboratory, NOAA, Princeton University Forrestal Campus, 201 Forrestal Road, Princeton, New Jersey 08540, USA, ${ }^{3}$ National Center for Atmospheric Research, 1850 Table Mesa Drive, Boulder, Colorado 80305, USA. *e-mail: yin@email.arizona.edu. 


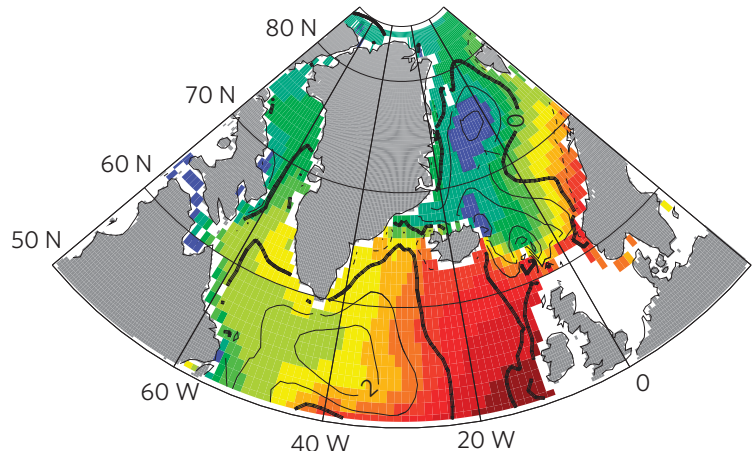

c

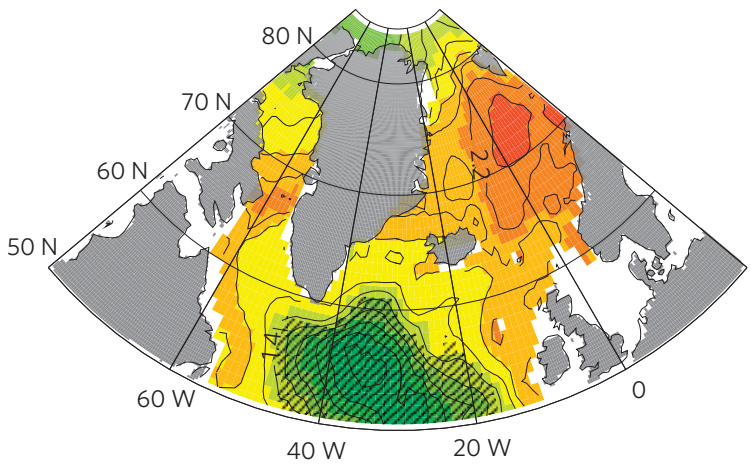

e

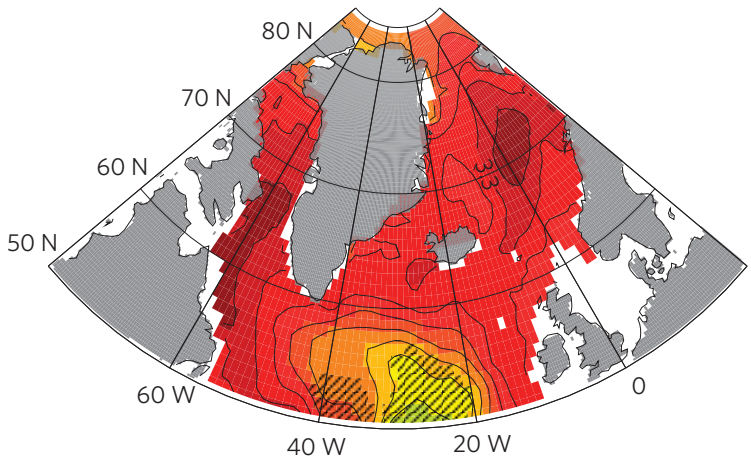

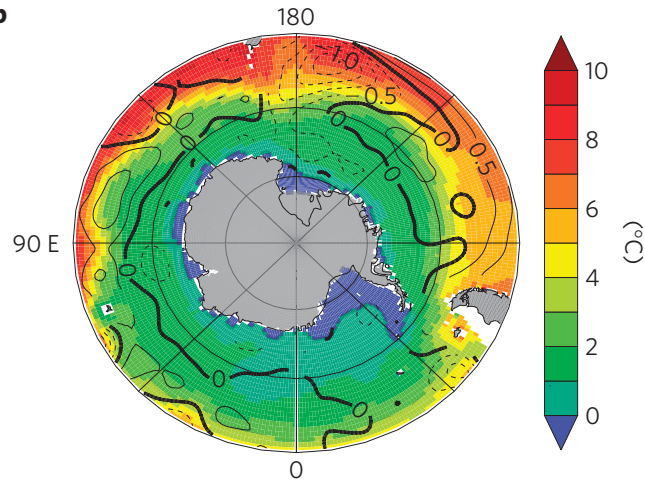

d

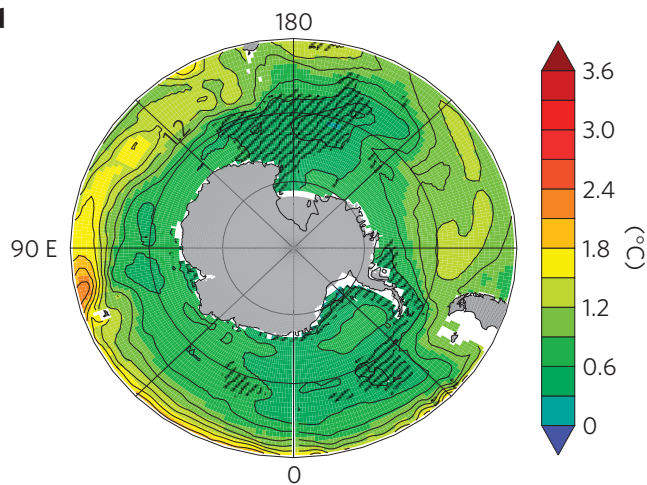

f

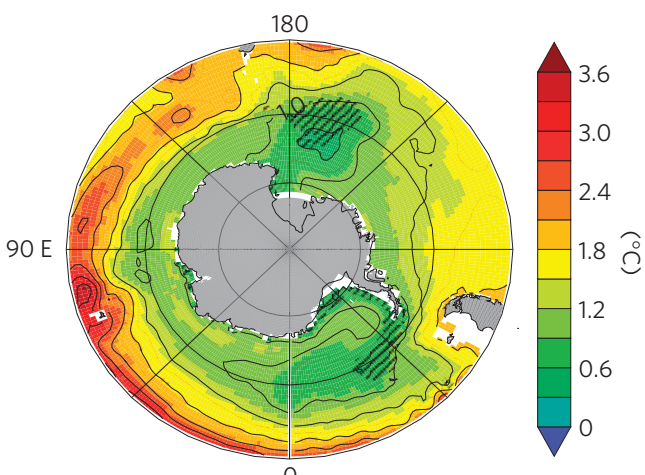

Figure 1 | Recent observed and ensemble mean projections of subsurface (200-500 m) ocean temperatures under the A1B scenario. a,b, Observed annual mean temperature during 1951-2000 (ref. 18) (shading) and the bias of the ensemble mean simulation by 19 AR4 models (contours). c,d, Projected anomalies by 19 AR4 models during 2091-2100. e,f, Projected anomalies by 13 AR4 models during 2191-2200. Stippling in c-f indicates the ensemble mean divided by the ensemble standard deviation is less than one, identifying regions where the models show less agreement.

CM2.0 and CM2.1 (Fig. 4 and Supplementary Fig. S3), respectively, because of the reduced air-sea temperature differential. In addition, the ocean surface freshening causes increased ocean stratification and a strong warming of the Atlantic intermediate water in the Nordic Seas (Supplementary Fig. S4).

The northward heat transport across the Iceland-Scotland ridge changes very slightly over the twenty-first century (Fig. 4). The heat accumulation in the Nordic Seas is mainly compensated in CM2.0 by an increase in the westward heat transport (37 TW) towards the GIS and subsequent southward transport across the Greenland-Iceland ridge (40 TW). This behaviour differs from the significant increase in the eastward heat transport (25 TW) into the Barents Sea in CM2.1, and less subsurface warming and sea-ice change along NE Greenland (Supplementary Figs S2 and S6).

The GIS feels the warmest ocean temperatures $\left(4-5^{\circ} \mathrm{C}\right)$ at its SE margin (Fig. 1a). The Irminger current directly brings warm and salty subtropical waters and mixes with the cold and fresh polar waters along SE Greenland. Thus the outlet glaciers in this region can be very sensitive to ocean changes in the low latitudes. In the past decade, the most significant net mass loss of the GIS occurred in this region, with remarkable acceleration of Helheim and Kangerdlugssuaq Glaciers ${ }^{1,4}$. Over the twenty-first century, the ocean surface heat loss south of Iceland reduces by about $100 \mathrm{TW}$ in both models (Supplementary Fig. S3), which is mainly compensated by the significant reduction of the northward heat transport at $45^{\circ} \mathrm{N}$ (Fig. 4). The warmer subtropical waters are pronounced along the route of the Irminger current and the ice sheet/ocean interface (Supplementary Fig. S4). The greater coastal warming in CM2.0 is linked to the increased southward heat transport across the Greenland-Iceland ridge (Fig. 4).

Unlike CM2.0, CM2.1 simulates a vigorous deep convection in the Labrador Sea during the twentieth century ${ }^{19}$, which attracts much heat into this ocean region (Fig. 4b). It weakens significantly over the twenty-first century. The oceanic heat transport by 


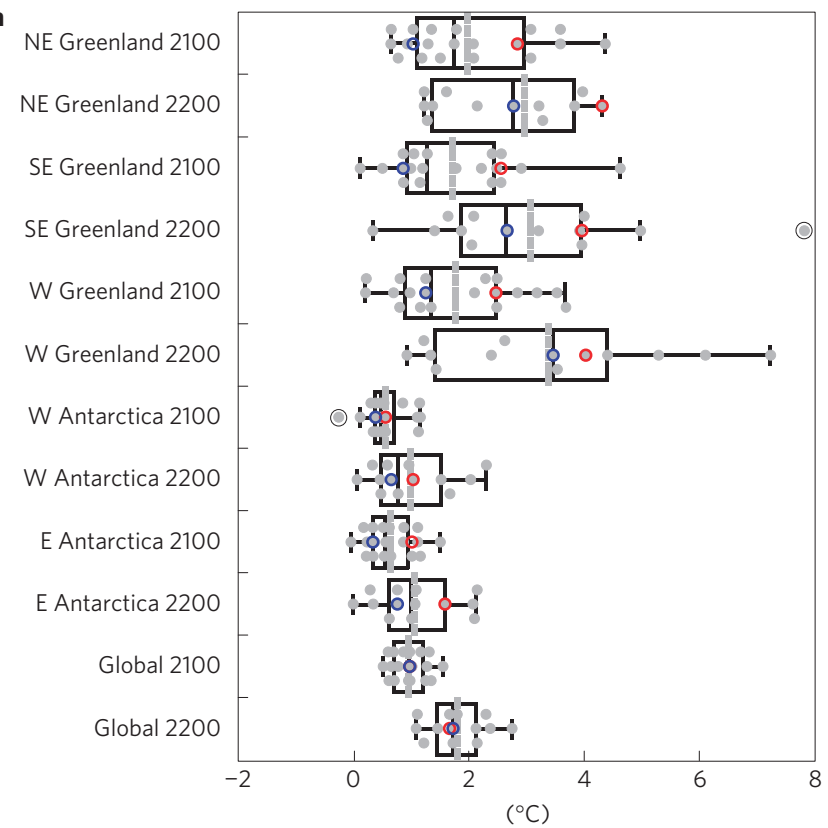

b

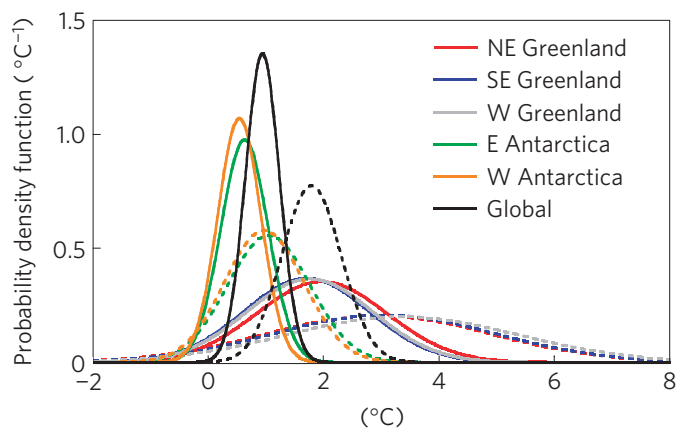

Figure 2 | Projections of subsurface ocean warming during 2091-2100 and 2191-2200 under the A1B scenario. a, A box plot of the warming along the land-ocean boundary of Greenland and Antarctica, together with the global mean in the same layer. Boxes show the median, 75th and 25th percentile, and whiskers indicate 95th and 5th percentile values in the ensemble. Grey dots and dashed lines indicate the projections by individual models and the ensemble mean, respectively. Red and blue circles indicate the GFDL CM2.0 and CM2.1 results, respectively. b, Probability density function for a Gaussian distribution fitted to the model ensemble for 2091-2100 (solid) and 2191-2200 (dashed) projections.

advection from the Irminger Sea to the Labrador Sea reduces by 30 and 183 TW in CM2.0 and CM2.1, respectively (Fig. 4). This difference results in less warming of the Labrador Sea in CM2.1 (Supplementary Figs S2 and S4). By 2200, however, both models project a substantial subsurface warming of above $4{ }^{\circ} \mathrm{C}$ along $\mathrm{W}$ Greenland. In contrast to the seas east of the GIS, the Labrador Sea and Baffin Bay are small and semi-enclosed, so their temperatures can change more dramatically in response to anomalous heat flux. The recent rapid acceleration of Jakobshavn Isbræ reflects its vulnerability to ocean warming ${ }^{1,3}$.

Climate models are more consistent in projecting a smaller ocean warming around Antarctica (Fig. 2). The Southern Ocean is characterized by steep isopycnals and strong temperature transition zones in $40^{\circ}-60^{\circ} \mathrm{S}$ (Fig. 3 and Supplementary Fig. S4). The ocean becomes very homogenous south of $60^{\circ} \mathrm{S}$ and is occupied by Circumpolar Deep Water with temperatures of -1 to $1^{\circ} \mathrm{C}$. In contrast to the EGC and WGC, the ACC is a very deep system and a strong barrier to poleward heat transport in all ocean layers. Over the twenty-first century, the westerlies in the Southern Hemisphere strengthen and shift southward in both models (Supplementary Fig. S7). The resultant intensification of the ACC, Ekman-induced upwelling of cold deep waters, and the meridional overturning in the Southern Ocean effectively blocks poleward propagation of ocean warming signals (Supplementary Figs S5 and S7). In contrast, there is no such blocking in the northern high latitudes, and warmer subtropical waters can penetrate all the way into the polar region around Greenland.

CM2.0 and CM2.1 project an increase in the heat transport from the east to west Antarctic Ocean (Fig. 4). The surface heat loss reduces in CM2.1. The resulting heat accumulation around the WAIS is compensated by the increased northward heat transport at $60^{\circ} \mathrm{S}$. Vigorous meridional heat transport takes place north of $60^{\circ} \mathrm{S}$, associated with the meandering of the ACC (Fig. S8). Ocean homogeneity south of $60^{\circ} \mathrm{S}$ remains unchanged, leading to small changes of heat transport by the Weddell Gyre and Ross Gyre. In contrast to the northern polar oceans surrounded by land, the Antarctic Ocean is bounded only to the south and characterized by strong wind-induced vertical mixing. This mixing tends to homogenize ocean warming and limit its magnitude in response to external forcing ${ }^{20}$.

As a result of the large heat capacity of sea water, ocean warming can efficiently melt ice at the ice sheet/ocean interface. It influences the two polar ice sheets in different ways. The ocean warming mainly changes the dynamics of the outlet glaciers of the land-based GIS, causes their acceleration and increases their drainage into the ocean at the early stage of GIS melt. Once the outlet glaciers retreat significantly and eventually become land-terminating, the ocean can only indirectly influence the GIS through the atmosphere. By contrast, warm waters persistently erode the marine-based portions of the AIS. The projected ocean warming around Antarctica, which is much larger than the recently observed changes ${ }^{6-8}$ and will continue beyond 2200 (ref. 21), has the potential to cause partial AIS disintegration once a tipping point is passed ${ }^{22,23}$. Indeed, the projected warming over the twenty-first century can be comparable to the last interglaciation about 129-118 thousand years ago, when global sea level was 4-6 m or more higher ${ }^{24,25}$, probably associated with a partial AIS collapse induced by ocean warming ${ }^{24}$.

Most contemporary climate models project a weakening of the Atlantic meridional overturning circulation (Supplementary Fig. S5) and a regional cooling or minimum atmospheric warming around Greenland during the twenty-first century ${ }^{16}$. This weakening is regarded as an important negative feedback that could protect the GIS in a warming climate ${ }^{26}$. However, our results and idealized freshwater addition experiments ${ }^{27}$ show that a maximum warming occurs in the subsurface ocean layer around Greenland. Given small seasonal temperature variation below $200 \mathrm{~m}$, subsurface ocean warming can induce a year-round melting of polar ice sheets, including winter. Our results indicate that because of reduced air-sea heat exchange, the heat absorbed by the ocean is more likely to circulate at the high latitudes and cause melting at the ice sheet/ocean interface. Although the feedback of meltwater on ocean warming is not fully taken into account, available model simulations ${ }^{28}$ suggest that it has a very small impact on subsurface ocean warming ( Supplementary Information and Fig. S9). In addition, palaeoclimate research shows that past massive iceberg discharge events (Heinrich events) in the northern North Atlantic lagged the weakening of the overturning circulation and were closely related to subsurface ocean warming ${ }^{29,30}$.

This study focuses on future ocean warming around the icesheet periphery controlled by large-scale dynamics, which provides background for more localized temperature changes. More accurate simulation and projection of ice sheets and their interactions with the ocean and the atmosphere require refined resolution Earth system models, which resolve fast-moving ice flows and small-scale temperature changes such as in fjords and under ice shelves. Until 

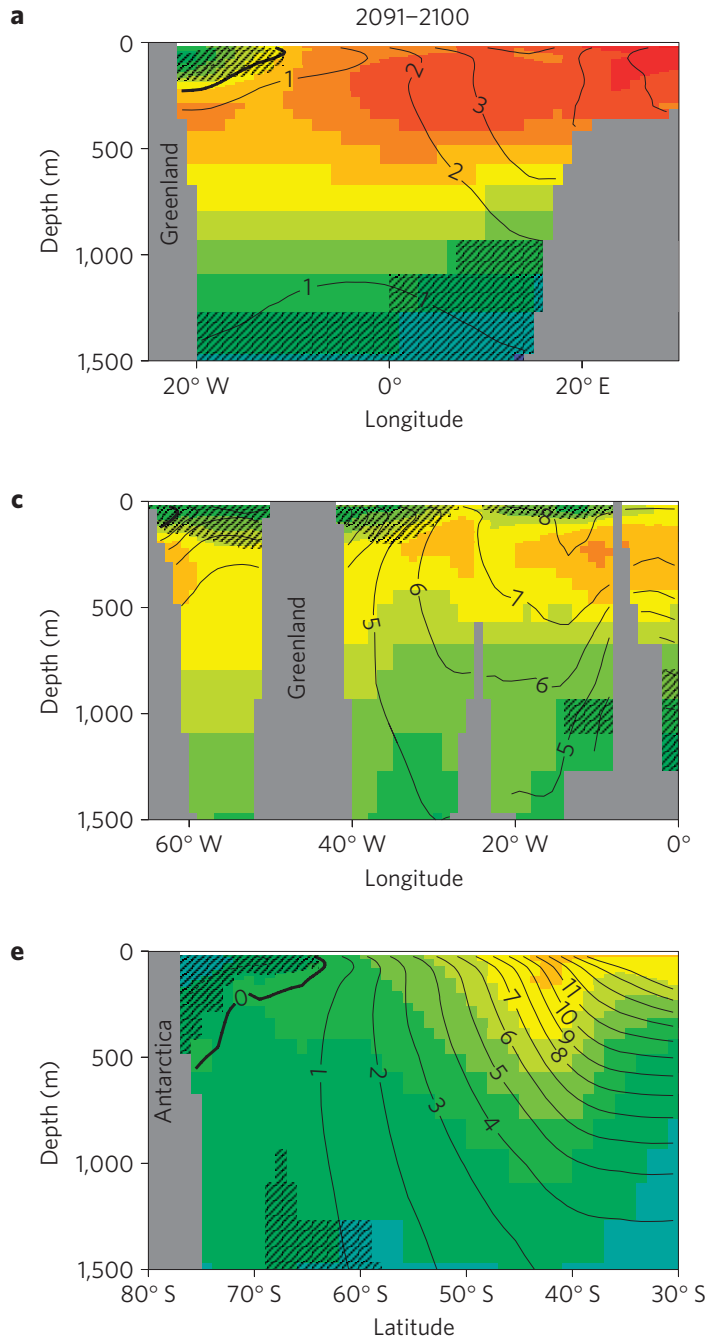

b

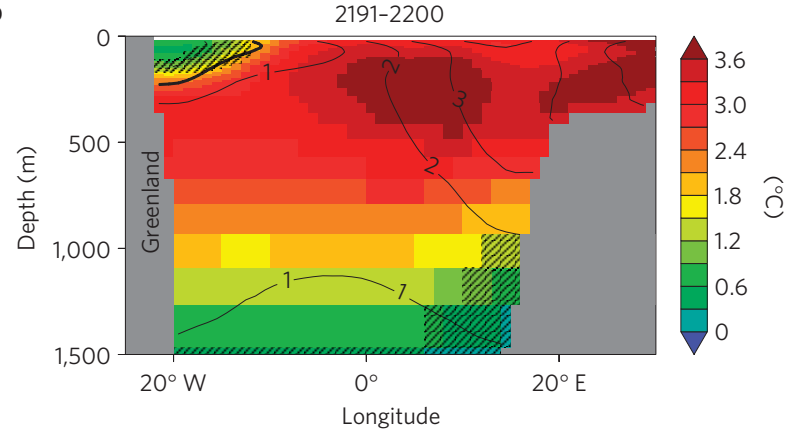

d
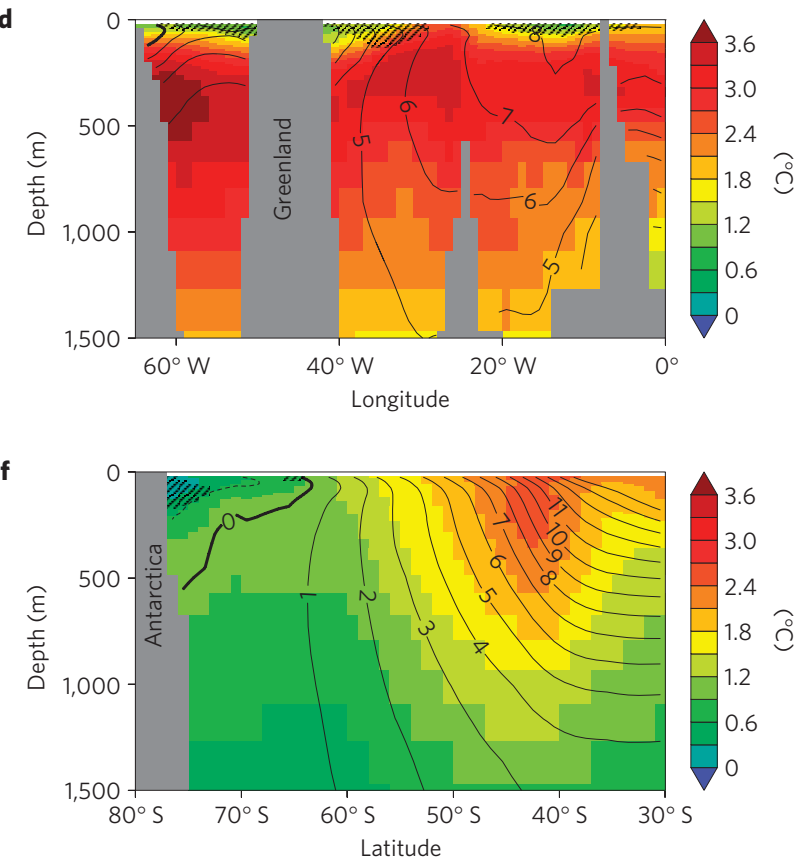

Figure 3 Ocean warming as a function of depth. Ensemble mean projections of ocean warming (shading) $\mathbf{a}, \mathbf{b}$, at $73^{\circ} \mathrm{N} ; \mathbf{c}, \mathbf{d}$, at $63^{\circ} \mathrm{N} ; \mathbf{e}, \mathbf{f}, z \circ n a l$ mean in the Southern Ocean. Left and right panels show the warming during 2091-2100 and 2191-2200, respectively. Contours show the simulated ocean temperature during 1991-2000. Stippling indicates regions where the models show less agreement.

the availability of these models, our results suggest substantial dynamic ice-sheet mass loss due to continued ocean warming should be considered a real possibility.

\section{Methods}

We examine the ocean climate projections by 19 climate models under the Intergovernmental Panel on Climate Change's (IPCC) Special Report on Emissions Scenarios (SRES) A1B scenario, which assumes modest reductions in greenhouse-gas emissions after mid-twenty-first century ${ }^{16}$. Greenhouse-gas concentrations are kept constant after 2100 . We consider three geographic regions for Greenland to calculate the regional mean: northeast (NE; $69^{\circ}-80^{\circ} \mathrm{N}$ ), southeast $\left(\mathrm{SE} ; 60^{\circ}-69^{\circ} \mathrm{N}\right)$ and west $\left(\mathrm{W} ; 60^{\circ}-75^{\circ} \mathrm{N}\right)$, and two regions for Antarctica: east (E; $\left.0^{\circ}-180^{\circ} \mathrm{E}\right)$ and west $\left(\mathrm{W} ; 180^{\circ}-360^{\circ} \mathrm{E}\right)$.

The GFDL CM2.0 and CM2.1 are fully coupled atmosphere-ocean general circulation models ${ }^{17}$. The horizontal resolution of the atmospheric model and land model in CM2 is $2.5^{\circ}$ longitude by $2^{\circ}$ latitude. The atmospheric model has 24 vertical levels. The oceanic component is a Boussinesq free-surface general circulation model, which explicitly represents the freshwater flux at the ocean surface. It employs $1^{\circ}$ horizontal resolution with the meridional resolution refined to $1 / 3^{\circ}$ in the tropics. It uses a depth vertical coordinate and has 50 levels, with 22 levels in the upper $220 \mathrm{~m}$. The dynamical-thermodynamical sea-ice model calculates ice internal stresses using the elastic-viscous-plastic technique. The vertically integrated oceanic heat transport in $\mathrm{CM} 2$ is

$$
\mathbf{F}=\rho_{0} c_{\mathrm{p}} \int_{-H}^{h}\left(\mathbf{v} \theta+\mathbf{F}_{\mathrm{sgs}}\right) \mathrm{d} z
$$

where $c_{\mathrm{p}}$ is the seawater heat capacity, $\rho_{0}$ is the reference seawater density, $\mathbf{v}$ and $\theta$ are velocity and potential temperature, respectively. $h$ is the deviation of the ocean's free surface from a state of rest. $H$ is the depth of the solid earth beneath the ocean. $F_{\mathrm{sgs}}$ is the oceanic heat flux arising from parameterized subgrid scale eddy processes. See Supplementary Information for more details.

Because CM2.0 and CM2.1 do not incorporate a dynamic ice-sheet model, the mass loss through ice-sheet dynamics is not simulated and projected. Land-ice calving is estimated using a very simple scheme and is dumped at the land-sea boundary without the transfer of icebergs away from land. Calving is treated as a solid water flux into the ocean, whereby the liquid ocean heat of fusion is extracted to melt the calved land ice. So there is an introduction of fresh water as well as heat flux (a cooling) associated with calving land ice. CM2 can represent surface melting through thermodynamic processes. The meltwater flows into the nearby oceans as runoff. For Antarctica, the ice shelves are considered solid boundaries. There is no water under the ice shelves in CM2.

Received 20 March 2011; accepted 23 May 2011; published online 3 July 2011

\section{References}

1. Rignot, E. \& Kanagaratnam, P. Changes in the velocity structure of the Greenland Ice Sheet. Science 311, 986-990 (2006).

2. Howat, I. M., Joughin, I. R. \& Scambos, T. A. Rapid changes in ice discharge from Greenland outlet glaciers. Science 315, 1559-1561 (2007).

3. Holland, D. M., Thomas, R. H., De Young, B., Ribergaard, M. H. \& Lyberth, B. Acceleration of Jakboshavn Isbræ triggered by warm subsurface ocean waters. Nature Geosci. 1, 659-664 (2008).

4. Straneo, F. et al. Rapid circulation of warm subtropical waters in a major glacial fjord in East Greenland. Nature Geosci. 3, 182-186 (2010). 

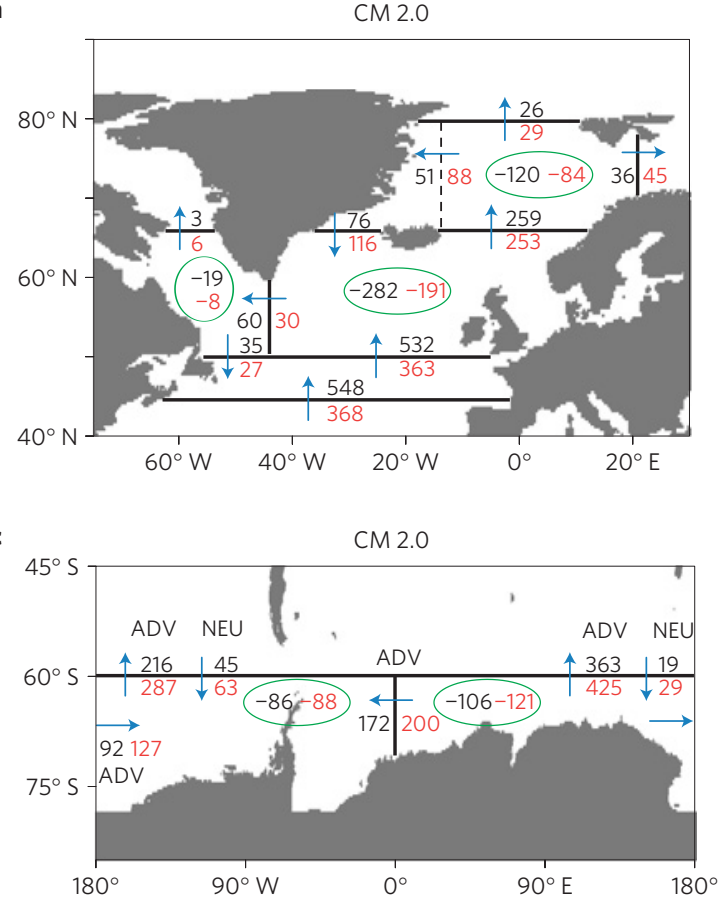

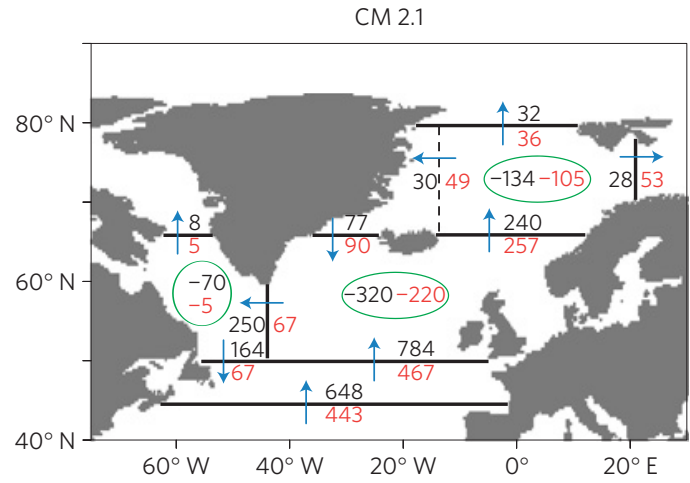

d

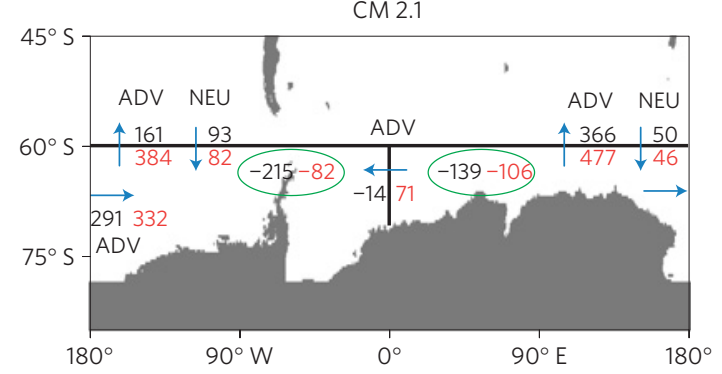

Figure 4 | Changes of ocean surface heat flux and ocean heat transport (TW). a,b, Ocean surface heat flux and heat transport by advection around Greenland. c,d, Ocean surface heat flux and heat transport by advection (ADV) and parameterized subgrid scale eddy (NEU) processes around Antarctica. Black and red colours indicate the values during 1991-2000 and 2091-2100, respectively. The numbers in the green circle indicate ocean surface heat gain in the areas surrounded by solid lines.

5. Rignot, E., Koppes, M. \& Velicogna, I. Rapid submarine melting of the calving faces of West Greenland glaciers. Nature Geosci. 3, 187-191 (2010).

6. Levitus, S., Antonov, J. \& Boyer, T. Warming of the world ocean, 1955-2003. Geophys. Res. Lett. 32, L02604 (2005).

7. Shepherd, A., Wingham, D. \& Rignot, E. Warm ocean is eroding West Antarctic Ice Sheet. Geophys. Res. Lett. 31, L23402 (2004).

8. Harrison, D. E. \& Carson, M. Is the world ocean warming? Upper-ocean temperature trends: 1950-2000. J. Phys. Oceanogr. 37, 174-187 (2007).

9. Moon, T. \& Joughin, I. Changes in ice front position on Greenland's outlet glaciers from 1992 to 2007. J. Geophys. Res. 113, F02022 (2008).

10. Oppenheimer, M. Global warming and the stability of the West Antarctic Ice Sheet. Nature 393, 325-332 (1998).

11. Thomas, R. et al. Accelerated sea-level rise from west Antarctica. Science 306, 255-258 (2004).

12. Rignot, E. et al. Recent Antarctic ice mass loss from radar interferometry and regional climate modeling. Nature Geosci. 1, 106-110 (2008).

13. Huybrechts, P. \& De Wolde, J. The dynamic response of the Greenland and Antarctic Ice Sheets to multiple-century climatic warming. J. Clim. 12, 2169-2188 (1999)

14. Gregory, J. M., Huybrechts, P. \& Raper, S. C. B. Threatened loss of the Greenland ice-sheet. Nature 428, 616 (2004).

15. Ridley, J. K., Huybrechts, P., Gregory, J. M. \& Lowe, J. A. Elimination of the Greenland ice sheet in a high $\mathrm{CO}_{2}$ climate. J. Clim. 17, 3409-3427 (2005).

16. Meehl, G. A. et al. in IPCC Climate Change 2007: The Physical Science Basis. Contribution of Working Group I to the Fourth Assessment Report of the Intergovernmental Panel on Climate Change (ed. Solomon, S.) 747-845 (Cambridge Univ. Press, 2007).

17. Delworth, T. L. et al. GFDL's CM2 global coupled climate models. Part I: Formulation and simulation characteristics. J. Clim. 19, 643-674 (2006).

18. Steele, M., Morley, R. \& Ermold, W. PHC: A global ocean hydrography with a high quality Arctic Ocean. J. Clim. 14, 2079-2087 (2001).

19. Stouffer, R. J. et al. GFDL's CM2 global coupled climate models. Part IV: Idealized climate response. J. Clim. 19, 723-740 (2006).

20. Manabe, S., Stouffer, R. J., Spelman, M. J. \& Bryan, K. Transient responses of a coupled ocean-atmosphere model to gradual changes of atmospheric $\mathrm{CO}_{2}$. Part I. Annual mean response. J. Clim. 4, 785-818 (1991).

21. Gillett, N. P., Arora, V. K., Zickfeld, K., Marshall, S. J. \& Merryfield, W. J. Ongoing climate change following a complete cessation of carbon dioxide emissions. Nature Geosci. 4, 83-87 (2011).

22. Weertman, J. Stability of the junction of an ice sheet and an ice shelf. J. Glaciol. 13, 3-11 (1974).
23. Kriegler, E., Hall, J. W., Held, H., Dawson, R. \& Schellnhuber, H. J. Imprecise probability assessment of tipping points in the climate system. Proc. Natl Acad. Sci. USA. 106, 5041-5046 (2009).

24. Overpeck, J. T. et al. Paleoclimatic evidence for future ice-sheet instability and rapid sea-level rise. Science 311, 1747-1750 (2006).

25. Kopp, R. E., Simons, F. J., Mitrovica, J. X., Maloof, A. C. \& Oppenheimer, M. Probabilistic assessment of sea level during the last interglacial stage. Nature 462, 863-867 (2009).

26. Fichefet, T. et al. Implications of changes in freshwater flux from the Greenland ice sheet for the climate of the 21st century. Geophys. Res. Lett. 30, 1911 (2003).

27. Mignot, J., Ganopolski, A. \& Levermann, A. Atlantic subsurface temperatures: Response to a shutdown of the overturning circulation and consequences for its recovery. J. Clim. 20, 4884-4898 (2007).

28. Hu, A., Meehl, G. A., Han, W. \& Yin, J. Transient response of the MOC and climate to potential melting of the Greenland Ice Sheet in the 21st century. Geophys. Res. Lett. 36, L10707 (2009).

29. Rasmussen, T. \& Thomsen, E. The role of the North Atlantic drift in the millennial timescale glacial climate fluctuations. Palaeogeogr. Palaeoclimatol. Palaeoecol. 210, 101-116 (2004).

30. Flückiger, J., Knutti, R. \& White, J. W. C. Oceanic processes as potential trigger and amplifying mechanisms for Heinrich events. Paleoceanography 21, PA2014 (2006).

\section{Acknowledgements}

We thank J. Gregory for constructive comments and many others at GFDL for carrying out the AR4/CMIP3 integrations. We also thank the Program for Climate Model Diagnosis and Intercomparison (PCMDI) for data archiving.

\section{Author contributions}

J.Y. initiated the study, performed data analysis and led the writing of the paper. J.T.O. and J.L.R. contributed expertise on palaeoclimate, ocean circulation and ice-sheet melt. S.M.G. and R.J.S. contributed to the GFDL climate model experiments. A.H. contributed to the NCAR climate model experiments. All authors contributed to discussion, interpretation of the results and writing of the manuscript.

\section{Additional information}

The authors declare no competing financial interests. Supplementary information accompanies this paper on www.nature.com/naturegeoscience. Reprints and permissions information is available online at http://www.nature.com/reprints. Correspondence and requests for materials should be addressed to J.Y. 